\title{
Correction to: Active sensing in a dynamic olfactory world
}

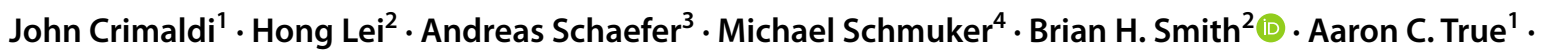 \\ Justus V. Verhagen ${ }^{5}$. Jonathan D. Victor ${ }^{6}$
}

Published online: 2 December 2021

(C) Springer Science+Business Media, LLC, part of Springer Nature 2021

\section{Correction to: Journal of Computational Neuroscience https://doi.org/10.1007/s10827-021-00798-1}

The article Active sensing in a dynamic olfactory world, written by Brian $\mathrm{H}$. Smith, was originally published online on 30 September 2021 with Open Access under a Creative Commons Attribution (CC BY) license 4.0.

With the author's decision to cancel Open Access the copyright of the article changed on 08 October 2021 to $($ ) Springer Science + Business Media, LLC, part of Springer Nature 2020 with all rights reserved.

Publisher's Note Springer Nature remains neutral with regard to jurisdictional claims in published maps and institutional affiliations.

The original article can be found online at https://doi.org/10.1007/ s10827-021-00798-1.

Brian H. Smith

brian.h.smith@asu.edu

1 Civil, Environmental, and Architectural Engineering, University of Colorado Boulder, Colorado 80309, USA

2 School of Life Sciences, Arizona State University, Phoenix, AZ 85287, USA

3 Department of Neuroscience, Physiology and Pharmacology, University College London and The Francis Crick Institute, 1 Midland Road, London NW1 1AT, United Kingdom

4 Biocomputation Group, University of Hertfordshire, College Lane, Hatfield AL10 9AB, United Kingdom

5 John B. Pierce Laboratory \& Dept. Neuroscience, Yale School of Medicine, New Haven, CT 06519, USA

6 Feil Family Brain and Mind Research Institute, Weill Cornell Medical College, New York, NY 10065, USA 